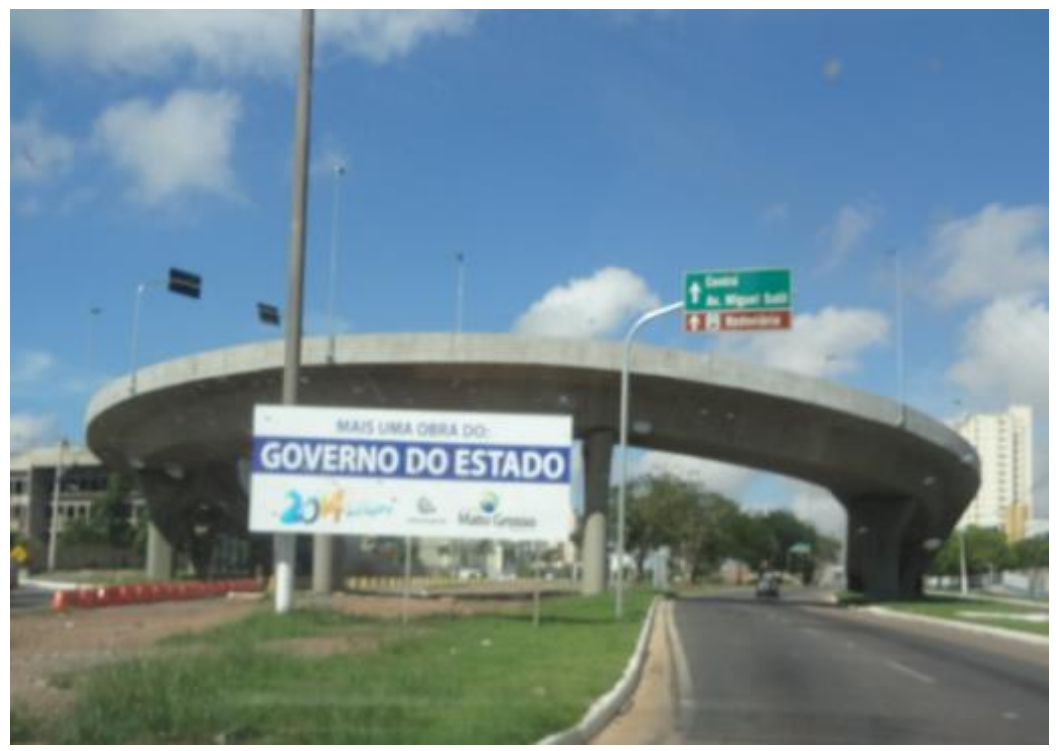

\title{
Cidade e futebol: um acontecimento político nos escritos em Cuiabá
}

City and soccer: a political event on writing, in Cuiabá

\author{
Ana Luiza Artiaga R. da Motta* \\ Ana Di Renzo
}

Resumo: Este artigo consiste em discutir os efeitos de sentido dos escritos urbanos, produzidos a partir do acontecimento futebolístico da Copa do Mundo de 2014, no Brasil. A materialidade simbólica, disponibilizada pelo Estado, em uma das cidades-sedes dos jogos permite que se pense a interpretação, as condições ideológicas de produção e transformação, do espaço urbano, em prol da mobilidade.

Palavras-chave: cidade, escrita, espaço, mobilidade, futebol.

Abstract: This article consist at discussing the sense effects of urban writing, produced from the soccer event of World Cup 2014, in Brazil. The symbolic materiality, provided by the State, in one of the host cities of the games allows us to think the interpretation, the ideological conditions of productions and transformation, in the urban space, for mobility.

Keywords: city, writing, space, mobility, soccer.

\footnotetext{
* Professoras do Departamento de Letras e do Programa de Pós-graduação em Linguística/UNEMAT. Pesquisadoras do CEPEL. Trabalho produzido nos projetos "Cidade e Memória" e "Ciência, língua e ensino"/CNPq, em especial, aos 20 anos da Revista Rua. analuizart@unemat.br e arenzo@unemat.br. Avenida Tancredo Neves, 1025 cavalhada 78200000 - Cáceres, MT - Brasil
} 


\section{Introdução}

Este trabalho tem como proposição pensar a escrita de placas, produzida em Cuiabá-MT, uma das cidades-sede dos jogos da Copa do Mundo de 2014. O acontecimento futebolístico, no Brasil, fez com que o Estado movesse o olhar sobre a cartografia, a geografia ${ }^{1}$ da cidade e a precisasse em obras de mobilidade urbana.

Para Lefebvre (2001), a cidade "é uma obra". "Com efeito, a obra é valor de uso e o produto é valor de troca” (p.4). Em meio à obra, o espaço é ordenado pelo simbólico das letras, do desenho gráfico dos mapas, quadras recortadas por ruas. Distintas formas de organização, de sentidos (ORLANDI, 2004) ao que se nomeia como cidade.

Conforme Le Goff (1998), o termo cidade tem um percurso histórico importante posto que a palavra "ville", usada para se denominar a cidade, é de conhecimento recente. Lembra que até o século XI e XII, a escrita era em latim e para nomear a cidade usou-se designações como "civitas", "cité" ou ainda "urbes". Enfatiza que o termo "ville", antigamente, designava o estabelecimento rural importante e de pertencimento ao senhor, o qual era compreendido como sendo o centro de poder não apenas pelo econômico, mas, sobretudo, em relação aos trabalhadores que viviam em redor das terras do senhor. Le Goff (op.cit.) Pontua que ao se designar a cidade na língua francesa de "la ville", o italiano se valerá do conservadorismo e manterá o termo "Città". Para o autor esse movimento de tomada de distintas posições no uso da língua para referir-se ao termo cidade marcará, necessariamente, as formas de poder do campo para o espaço da cidade. Em recorrência a esse movimento histórico diz que "o termo "villa" se aplicará à aldeia nascente a partir dos séculos IX e X.

A cidade, segundo Le Goff (1998), vai tomando corporeidade, urbanidade, a partir de núcleos que dá visibilidade ao povoado, e gradativamente o espaço do poder é subdividido e cingido pelas diferenças que o espaço institui entre o campo, o burgo da periferia e o centro. Dessa maneira, a cidade torna-se porosa e o poder que ela emana reclama sentidos.

Do ponto de vista da linguagem, a cidade nos move a gestos de interpretação ${ }^{2}$ que se depreende da paisagem urbana, dos escritos que permeiam as ruas, materializados pelas placas. Porém, com que sentido os espaços são textualizados pelos escritos em um acontecimento?

\footnotetext{
${ }^{1}$ Ver Rolnik, 1999.

${ }^{2}$ Orlandi (1996). Interpretação: autoria, leitura e efeitos do trabalho simbólico.
} 
Para Rancière (1995), “o conceito de escrita é político porque é o conceito de um ato sujeito a um desdobramento e a uma disjunção essenciais" (p.07). Continuando, o autor diz que o "ato de escrever é uma maneira de ocupar o sensível e dar sentido a essa ocupação" (p.07). O espaço em que se dá visibilidade à escrita é um modo de dar sentido.

Para Santos (2002), o termo espaço não tem um conceito, há uma multiplicidade de expressões como: "espaço urbano, espaço mental, espaço político, espaço sideral, espaço social" [...] (p.16). Ou seja, um modo de nomear, de direcionar o lugar que se ocupa.

O uso de escrita em placas é um modo de dizer e tem a ver com a formação ideológica de quem a produz. Conforme Pêcheux (1995), não se deve esquecer que o sentido não existe "em si mesmo", "mas, ao contrário, é determinado pelas posições ideológicas que estão em jogo no processo sócio-histórico no qual as palavras, expressões e proposições são produzidas" (p.160). Daí, a necessidade de se analisar os escritos em uma situação x, em que tomam corporeidade.

\section{Cidade e escrita: a bola da vez nos escritos de Cuiabá}

A cidade de Cuiabá-MT, fundada em 1719 por Pascoal Moreira Cabral Leme, tornou-se um dos espaços cidades-sede dos jogos do Mundial de 2014. A evocação do poder local, como espaço político-esportivo, produz a interpelação ideológica da cidade de se ajustar às normas determinadas pela FIFA.

A Copa do Mundo de 2014, no Brasil, tornou-se o acontecimento político que, enquanto fato, ideologicamente, intervém no real do sentido da cidade que sediará os jogos. O discurso político-esportivo impõe a mobilidade urbana e o poder local sofre as ingerências da mudança, da "metamorfose" da cartografia citadina.

Em Mato Grosso, o Estado espacializa placas que estabelecem uma relação de sentidos outros com o corpo urbano, com o sujeito. Em uma palavra, expõe o olhar leitor às sinalizações, escritas de placas que mediatizam as 56 (cinquenta e seis) obras desenvolvidas na cidade. Dentre estas, o estádio, viadutos, Veículos Leve sobre Trilhos/VLT, pontes e avenidas que foram/deveriam ser construídas em função do evento esportivo, tornaram-se objetos de licitações comandadas pelo Estado.

A copa é no Brasil, e o país mobiliza e as cidades-sede que se movimentam e se inscrevem no discurso de ter que construir para jogar. O mercado imobiliário tomado pela especulação da mídia em relação ao território da cidade investe em propagandas de 
casas e condomínios. É o jogo de discursos e de marketing, que antecedem a Copa do Mundo/2014, é o que movimenta o tabuleiro de dama, que desenha a cidade e que faz pensar o poder que a atravessa em sua constituição física de cidade (RAMA, 1985).

A cidade, a cada época, tem se inscrito no tecido urbano, a posição sóciohistórica e ideológica da forma-sujeito que a gesta, a administra e disciplinariza os seus sentidos. Cuiabá, capital do Estado de Mato Grosso, construída pelo idealismo de cidade no Brasil colônia, em 1719, século XVIII, conta com uma arquitetura peculiar do período barroco, visíveis no centro histórico. Os casarões, igrejas, ruas estreitas, do centro histórico, remetem às determinações das leis afonsinas, à realidade física do desenho urbano para a passagem de pequenos automóveis, próprios à mobilidade da época.

Nessa linhagem, a cidade de Cuiabá, em sua morfologia, textualiza os traçados da cultura de um povo, da política de um Estado do Brasil colônia e que, no contemporâneo, reclama sentidos entre a ordem (simbólico) e a sua re-organização (estrutura) $)^{3}$.

\subsection{Textura urbana}

No Estatuto da Cidade, Lei Orgânica, há a escrituração, a projeção imaginária de cidade. Isto é, "A ordem deve ficar estabelecida antes que a cidade exista, para impedir assim toda futura desordem" (RAMA, 1985, P.29). Dito de outra forma, a lei é quem institui as diretrizes políticas que antecede o real, a cidade.

Dessa forma, a cidade se divide milimetricamente, demarcando múltiplos sentidos, escrituras, instituições, construções, nomes de ruas, materialidade simbólica. Em síntese, "tudo o que se nos apresenta, no mundo social-histórico, está indissociavelmente entrelaçado com o simbólico" (CASTORIADIS, 1982, p.142). Continuando, diz o autor que o simbólico constitui a teia da sociedade e que o encontramos primeiro na linguagem. Diz, ainda, em outros termos que as instituições se constituem e se significam pelo simbólico; ainda que as instituições não se reduzam a este simbólico, torna-se impossível o processo de instituição se não for pelo simbólico.

Não é importuno dizer que o efeito ideológico naturaliza os acontecimentos de linguagem, a materialidade simbólica em si, e assim as relações entre o homem e o mundo que nos parecem tão transparentes. Mas, é necessário questionar a história. Isto

\footnotetext{
${ }^{3}$ Ver Orlandi, 1999. Revista Rua. A autora discute a cidade entre a ordem e a organização.
} 
é, o processo sócio-histórico, pois “[...] não há "fato” ou "evento" histórico que não faça sentido, que não peça interpretação, que não reclame que lhe achemos causas e consequências" (HENRY, 1997, p. 51 e 52), e é isso, segundo o autor, que consiste a história, no fazer sentido. "Os fatos reclamam sentidos".

A escrita que media o espaço da cidade com o arquitetônico das obras requer leitura e interpretação, sobretudo, de forma não linear.

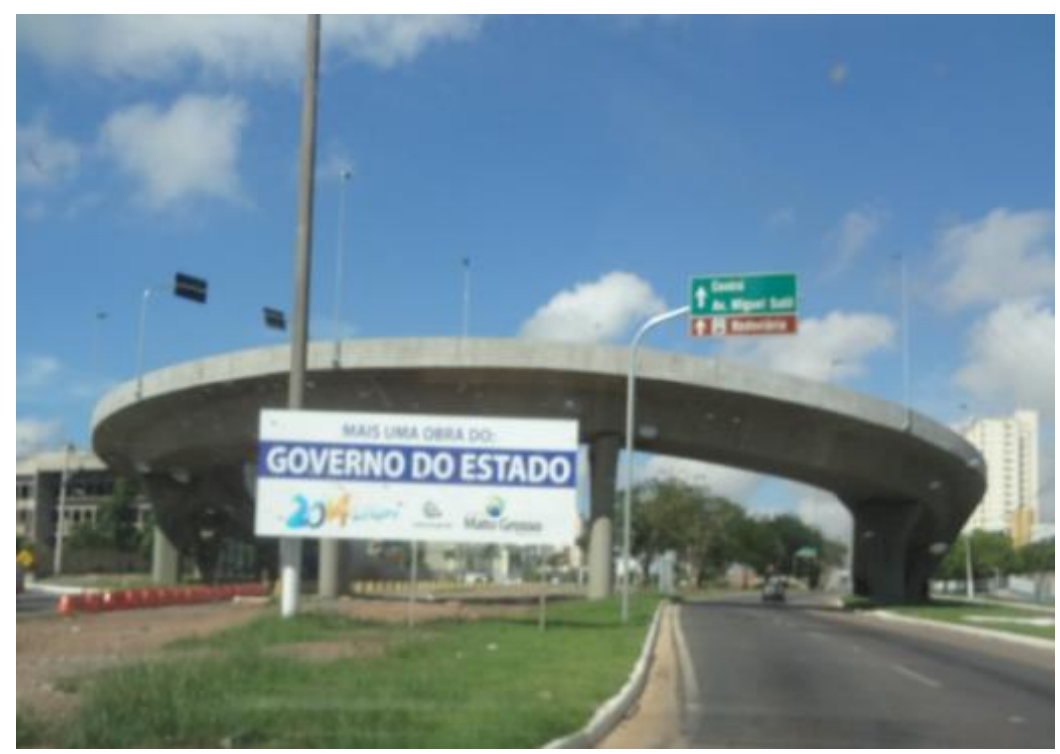

Figura 1

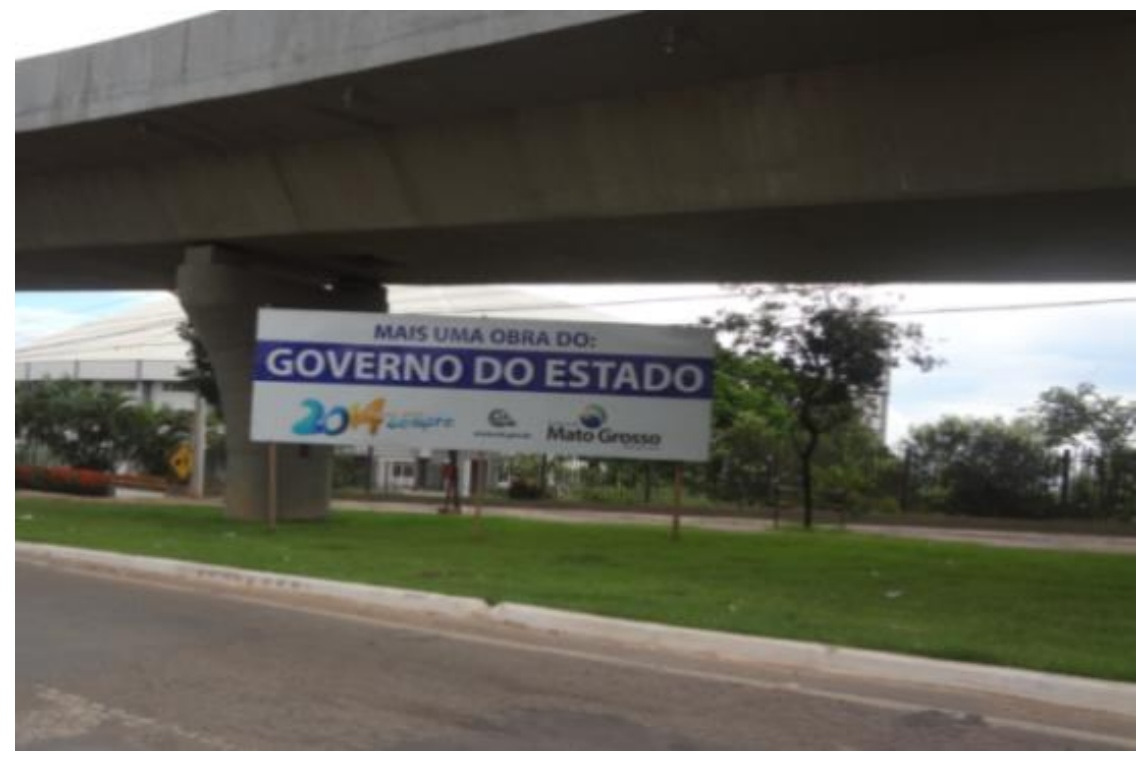

Figura $\mathbf{2}^{4}$

\footnotetext{
${ }^{4}$ As fotos, neste estudo, são arquivos nossos de estudos de placas de domínio público, na Avenida do CPA, Miguel Sutil, na cidade de Cuiabá-MT/2014.
} 
A cidade convergida na escritura da Copa do Mundo se espacializa nos dizeres do Estado. Placas sinalizam em letreiros a mobilidade do transeunte e remetem às obras em concreto armado em viadutos. Estas apontam para um mesmo dizer que se repete, funcionando ideologicamente sobre diferentes discursos políticos que antecedem 2014, em Cuiabá-MT.

Nas placas, as escritas (fig.01) e (fig.02), enunciada pelo Estado, expõe o jogo de sentidos entre a obra do viaduto e a formulação "mais uma obra do GOVERNO DO ESTADO". Esta inscrita, entre o branco e o azul, afloram sentidos, nas diferentes formações discursivas - a escrita e as cores - que remetem a Bandeira de Mato Grosso. No dizer "2014 será para sempre”, o Estado se coloca em uma posição futurística em que não se diz por que 2014 será uma data que edifica uma memória discursiva. Há um apagamento da filiação de sentidos que determinaram a construção do viaduto em Cuiabá. Ou seja, as construções filiam-se às cidades-sede, a um acontecimento de categorização mundial, os jogos da Copa do Mundo de 2014, no Brasil.

Na formulação "mais uma obra", o advérbio "mais" de intensidade enuncia a efusão ideológica daquele que está fazendo muito e que ao escrever, inscreve-se, faz circular sentidos à cidade. O Estado, discursivamente se coloca como aquele que edifica pelo concreto das construções uma memória que se perpetuará para sempre. De modo que nos enunciados, as escritas abrem para interpretação, a interpelação da posição do Estado e como este tende a se inscrever e a se fazer querer perpetuar no espaço ao referir-se que "2014 será para sempre".

Nessa linha de raciocínio tem-se um discurso que se quer se fazer como fundador pela flexão do verbo ser - será - flexionado no futuro do presente em que se lê "2014, será para sempre”. Será? Com que sentido? Institui-se um marco na linha do tempo em que os efeitos de sentido de 2014 não se encerram ao término dos doze meses. Ou seja, os sentidos não se fecham, os escritos evocam o acontecimento da Copa do Mundo, em Cuiabá. Esse fato reverbera sentidos e é o que faz inscrever o poder local em uma memória que não se lê/lerá como nacional, mas mundial. A questão é pensar, pelo funcionamento da língua, como o Estado concebe a sua inscrição de poder no espaço urbano. Rancière (1995, p. 08) diz que:

A escrita é política porque traça, e significa, uma re-divisão entre as posições dos corpos, sejam eles quais forem, e o poder da palavra soberana, porque opera uma re-divisão entre a ordem do discurso e a das condições. 
Pêcheux (1995) nos faz pensar, pelo discurso, que as relações são relações de poder. Esse autor nos faz compreender que, no discurso, o histórico, o social e o ideológico movimentam sentidos. Porém, pelo processo de naturalização da língua/linguagem apagam-se os efeitos ideológicos que atravessam o discurso e que tornam opaco o dizer, o lugar em que subjaz o poder.

Barthes (1978) dirá que “o poder está emboscado em todo e qualquer discurso, mesmo quando parte de um lugar fora do poder" (p.10). Em continuidade diz que o poder não é um objeto exemplarmente político, mas é, necessariamente, um objeto ideológico e de resistência. Aponta que:

A razão dessa resistência e dessa ubiquidade é que o poder é o parasita de um organismo trans-social, ligado à história inteira do homem, e não somente à sua história política, histórica. Esse objeto em que se inscreve o poder, desde toda eternidade humana, é: a linguagem - ou, para ser mais preciso, sua expressão obrigatória: a língua (BARTHES, 1978, p.12).

Barthes (op.cit.) expõe o poder que reside na língua. Pêcheux (1995) diz que não se tem discurso sem sujeito nem sujeito sem ideologia e que se tem acesso à ideologia pela materialidade específica do discurso e que a materialidade específica do discurso é a língua. Assim, a materialidade da língua constitui o lugar em que se tem acesso ao funcionamento da linguagem, o jogo que lhe é passível. Vejamos os escritos.

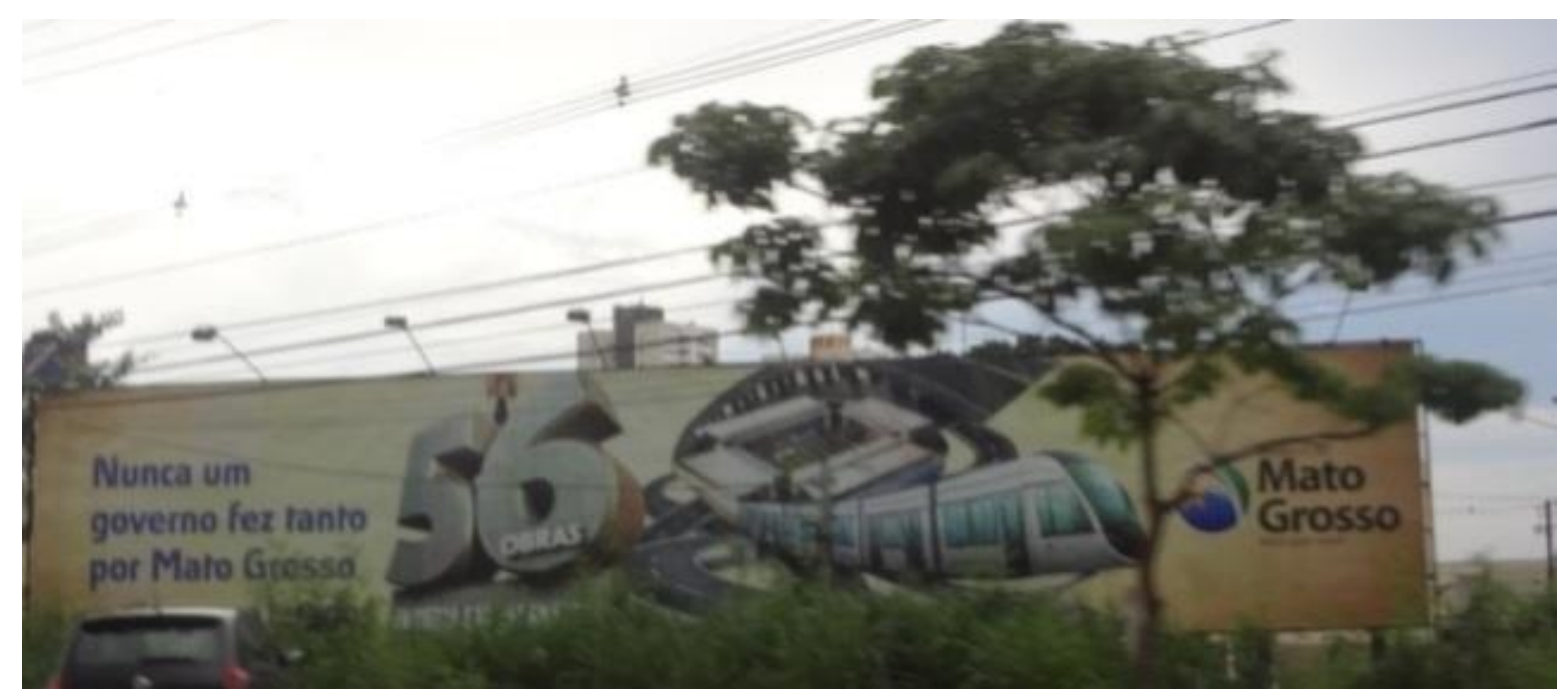

Figura 3 


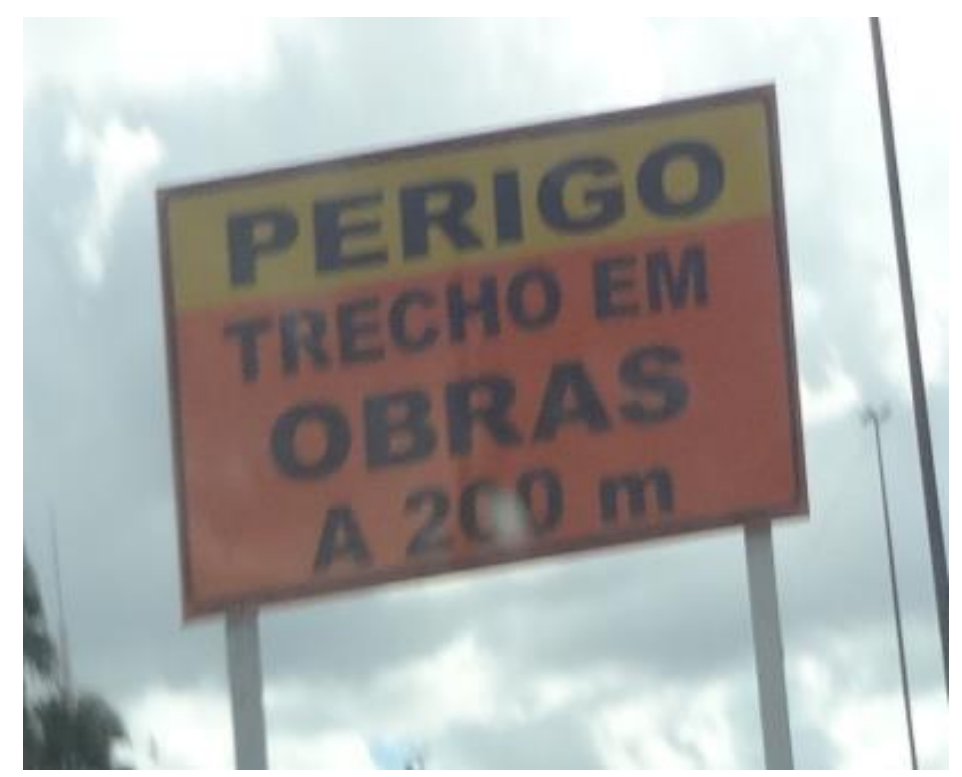

Figura 4

Na fig.03 se lê: "Nunca um governo fez tanto por Mato Grosso", "56 obras". Na formulação, o advérbio "nunca" temporaliza, determina a posição política do Estado, o governo, em relação à Mato Grosso. Em "Nunca um governo" silencia o investimento FIFA e produz como efeitos de sentido um revestimento ideológico do papel do governo: é ele quem fez 56 obras. Para Orlandi "há um modo de estar em silencio que corresponde ao modo de estar no sentido [...] Há silencio nas palavras" (ORLANDI, 1995, p.11). Isto posto, ao enunciar, o sujeito diz para não dizer, pois a palavra traz consigo também sentidos silenciados, posto que o silêncio também significa. Ou seja, os sentidos não formulados também convocam gestos de interpretação. Por isso, mesmo que ao dizer o sujeito não diz, aponta para o trabalho da ideologia na linguagem e mostra que o silencio é igualmente afetado por ela.

A placa exposta no espaço, de fluxo intenso, na cidade remete a efeitos de imediatismo. Isto é, em quatro anos, 56 obras. A formulação reverbera sentidos sobre o que não se diz, mas que a memória faz funcionar. Ou seja, tem-se um acontecimento, a copa do mundo, no poder local, que desestabiliza sentidos e apagam-se outros que se constituem no processo sócio-histórico e político de Cuiabá que soma em 2014, 294 anos. Nessa linha de raciocínio, enunciados como "Perigo, trecho em obras", tem-se um substantivo que produz como efeitos de sentido a responsabilização dos sujeitos pelos cuidados de si, pois a cidade está sendo remodelada sob a tutela do Estado que é quem chama a sua atenção para a situação de risco. Sentidos que se repetem também em outras capitais de estados brasileiros que sediaram os jogos da Copa do Mundo de 2014, 
interditando sentidos e espaços, e escriturando a cidade em mudanças. E como tal, abrem-se para a interpretação, jogam com o interlocutor, mobilizam-no ao se dar a ler a cidade.

A leitura é em si um acontecimento em que a língua se transforma e as significações são abaladas; as relações entre palavras, entre frases, se modificam; os mesmos segmentos lidos novamente trazem novos sentidos (NUNES, 1994, p.16).

A noção de leitura discutida por Nunes (op.cit.) pressupõe o movimento, o funcionamento da língua. Para Orlandi (1999), a leitura tem suas condições próprias, daí que os sentidos estão inerentes às condições da própria leitura, do sujeito. Dito de outro modo, "sujeitos e sentidos são elementos de um mesmo processo de significação" (p.10). Isto permite depreender que não se pode pensar que a leitura seja única, que há transparência no/do texto e que este dirige a leitura. Conforme Orlandi (idem), a leitura tem a ver com a historicidade "em que o simbólico (linguístico) e o imaginário (ideológico) se juntam - que constitui as condições de produção da leitura" (p.11).

De modo que ler a placa consiste em entender que sentidos atravessam a textura da placa que sinaliza a cidade. Novamente remetemos a Orlandi (op.cit.), que pontua, "saber ler é saber o que o texto diz e o que ele não diz mas o constitui significamente" (p.11). Ou seja, ler requer indagações. Assim, ao escrever na textura da cidade em placas e ou outra manifestação de linguagem como tarjas, pinturas entre outros, requer que reiteremos a instância ideológica, a materialidade simbólica. Vejamos o que segue.

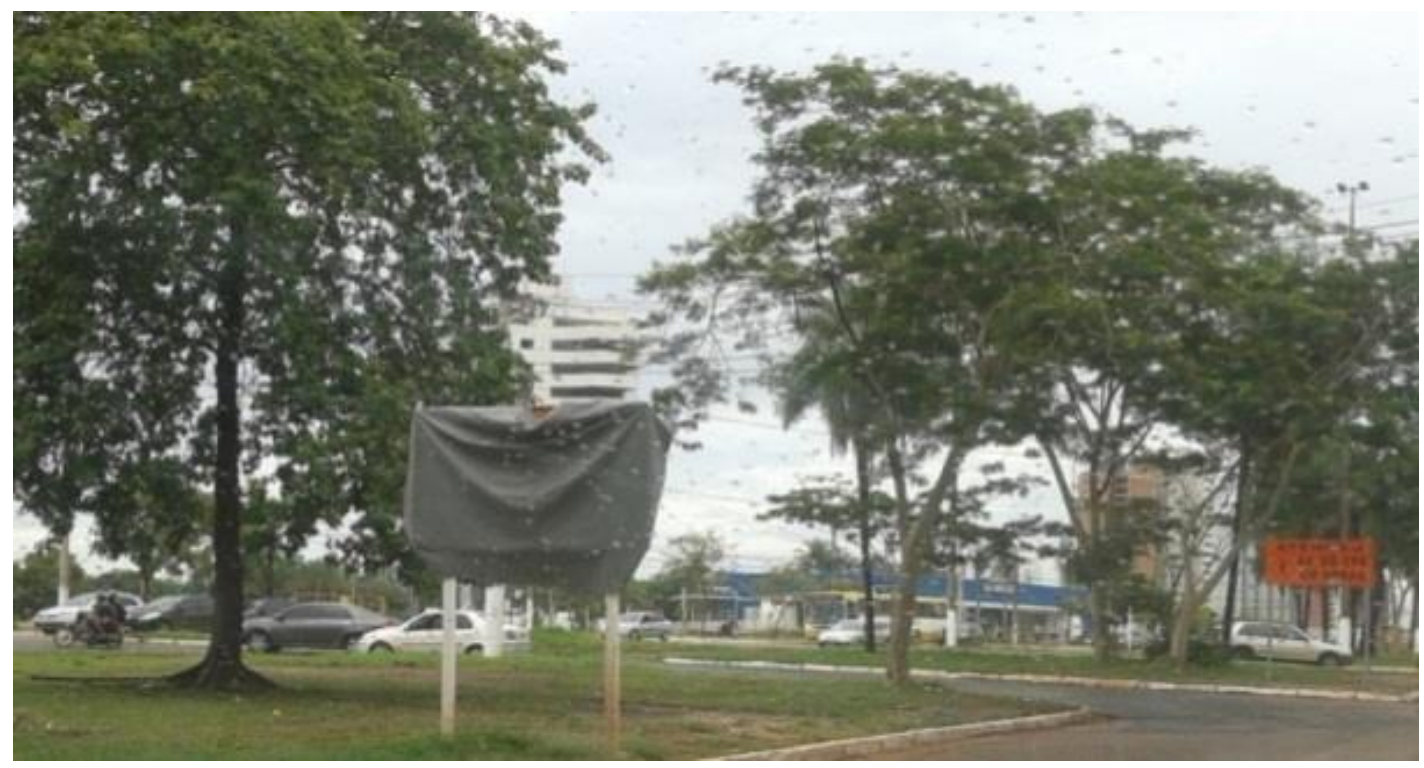

Figura 5 
A placa (fig.05) media a relação do sujeito com o espaço, expõe sentidos. A tarja que recobre a placa silencia acontecimentos que mediaram a escritura no tecido urbano, na cidade de Cuiabá-MT. Interdita, desestabiliza sentidos no trânsito urbano que sofre a interpelação de se readequar em função do jogo da Copa do Mundo. Uma leitura interdita, mas a presentificação da ação do Estado permanece. A cidade se mexe. Os dribles se dão pelos desvios. Pelos sentidos interditados.

O evento futebolístico movimenta a estrutura da cidade, determina o replanejamento, o fluxo, a mobilidade urbana. A palavra mobilidade torna-se pedra de toque, de uso fluído, no discurso veiculado pela mídia, pelo Estado, e por transeuntes que em confronto com os espaços modificados evocam sentidos.

\section{Considerações finais}

A cidade constitui um espaço físico que se dá a ler, a interpretá-lo. Do ponto de vista de Lefebreve (2001), a cidade é uma rede de poder ao que acrescentaríamos pelos estudos discursivos que a cidade é uma rede de sentidos, de trocas, traços que mediatizam os interlocutores.

Concluímos esta reflexão, entendendo que o discurso é opaco e que a escritura urbana constitui um espaço importante de leitura no real atravessado por distintas formações ideológicas. No caso das placas, no espaço da cidade, produz a interpelação ideológica. Dessa forma, faz-se necessário observar, no espaço da formulação, o movimento da língua em que se constitui o sentido. No caso do discurso de mobilidade urbana que mediatiza as cidades-sede, há que se perguntar sobre os sentidos transversos que se inscrevem e faz movimentar a memória o acontecimento.

Em suma, as distintas formulações que tomamos para análise fazem emergir pela sintaxe da língua que se faz necessário questionar a opacidade da escrita. Que o discurso não é por si um gesto simples, mecanicista.

De forma naturalizada, o discurso futebolístico que mundializa as relações, unifica o desejo de ganhar a Copa do Mundo e, consequentemente, modaliza o movimento das cidades, o país. Trata-se de um efeito ideológico, gesto que intervém no real do sentido de cada cidade que se redesenhou em 2014. Assim, abrem-se fendas no chão de Cuiabá, o tecido urbano é rasgado pelas trincheiras, e a morfologia que sustenta a cidade se remodela em prol do drible da bola, do jogo, que perdura em dois tempos de 45minutos que somam 90minutos e que eternizará "para sempre" 2014 e não a cidade, nem seus sujeitos. 
Escrever a cidade de Cuiabá no acontecimento da copa do mundo de 2014 dá visibilidade ao modo como a escrita disciplinariza sujeitos e sentidos, bem como expõe a língua afetada pelo trabalho da ideologia que faz, como efeitos de sentido, parecer que a nova morfologia do urbano é uma ação de governo e não de uma federação internacional. É pelo mecanismo de apropriação que os sujeitos têm seus sentidos capitaneados pelo discurso em prol da mobilidade urbana como condição de transitar pelos seus novos espaços.

\section{Referências}

CANEVACCI, Massimo. (2004). A cidade polifônica: ensaio sobre a antropologia da comunicação urbana. Trad. Cecilia Prada. - $2^{a}$ ed. São Paulo: Stúdio Nobel.

CASTELlS, M. A. (1983). Questão Urbana. Tradução Arlene Caetano. RJ: Paz e Terra.

CASTORIADIS, C. (1982). A Instituição Imaginária da sociedade. Tradução de Guy Reynaud, revisão técnica de Luiz Roberto Salinas Fortes. $5^{\text {a }}$ ed. RJ: Paz e Terra.

FERREIRA, João Carlos Vicente. (2001). Mato Grosso e seus Municípios. Cuiabá: Secretaria de Estado de Educação, Buriti.

HENRY, Lefebvre. (2001). O direito à cidade. Trad. Rubens Eduardo Frias. SP. Centauro.

HENRY, P. Apêndice: Sentido, Sujeito, Origem. (1993). In Discurso Fundador: a formação do país e a construção da identidade nacional. Campinas, SP. Pontes.

.(1997). A história não existe? In Gestos de Leitura: da história no discurso. Eni P. Orlandi (Org.) Tradução Bethânia Mariani [et.al] Campinas, SP: UNICAMP.

LEGOFF, Jaques. (1998). Por amor às cidades: conversações com Jean Lebrun. Trad. Reginaldo C. C. de Moraes. SP. Ed. UNESP.

MOTTA, A. L. A.R. (2011). Planejamento urbano: a voz da cidade. In Linguagem, história \& Memória: discurso em movimento. (Org.) Di Renzo, Ana; Motta, Ana Luiza A.R. \& Oliveira Tania Pitombo. Campinas, SP. Pontes.

ORLANDI, E. P. (1995). As formas do silêncio. No movimento dos sentidos. $3^{\text {a }}$ Ed. Campinas. Editora da UNICAMP. Vozes.

(1996). Interpretação: autoria leitura e efeitos do trabalho simbólico. Petrópolis, . (1999). N/O Limiar da Cidade. In. RUA, UNICAMP - NUDECRI. Campinas, SP. (2004). Cidade dos Sentidos. Campinas, SP. Pontes.

PÊCHEUX, M. (1995). Semântica e discurso: uma crítica à afirmação do óbvio. (trad.) Eni P.Orlandi. 2a . ed. Campinas, SP: UNICAMP.

(1997). O discurso: estrutura ou acontecimento. Trad. Eni P. Orlandi. $2^{\mathrm{a}}$ ed. Campias, SP. Pontes.

(1999). Papel da Memória. In. Papel da Memória. Campinas, SP. Pontes. 
RAMA. Angel. (1985). A cidade das letras. Tradução: Ed. Brasiliense.

RANCIÈRE, Jacques. (1995). Políticas da escrita. Trad. Raquel Ramalhete... [et al]. RJ. Ed.34.

ROLNIK, Raquel. (1999). A cidade e a lei: legislação, política urbana e territórios na cidade de São Paulo. $2^{\mathrm{a}}$ ed. São Paulo: Studio Nobel: Fapes.

SANTOS, Douglas. (2002). A reinvenção do espaço: diálogos em torno da construção do significado de uma categoria. SP. Ed. UNESP. 
Para citar essa obra:

MOTA, A. L. A. R.; RENZO, A. M. Cidade e futebol: Um acontecimento político nos escritos em Cuiabá In: RUA [online]. 2014, Edição Especial - ISSN 1413-2109. Consultada no Portal Labeurb - Revista do Laboratório de Estudos Urbanos do Núcleo de Desenvolvimento da Criatividade.

http://www.labeurb.unicamp.br/rua/

Capa: Arquivo das autoras. Avenida do CPA, Miguel Sutil, Cuiabá-MT.

Laboratório de Estudos Urbanos - LABEURB

Núcleo de Desenvolvimento da Criatividade - NUDECRI

Universidade Estadual de Campinas - UNICAMP

http://www.labeurb.unicamp.br/

Endereço:

LABEURB - LABORATÓRIO DE ESTUDOS URBANOS

UNICAMP/COCEN / NUDECRI

CAIXA POSTAL 6166

Campinas/SP - Brasil

CEP 13083-892

Fone/ Fax: (19) 3521-7900

Contato: http://www.labeurb.unicamp.br/contato 